EESTI NSV TEADUSTE AKADEEMIA TOIMETISED

FOUSIKA * MATEMAATIKA

ИЗВЕСТИЯ АКАДЕМИИ НАУК ЭСТОНСКОП ССР. ФИЗИКА * МАТЕМАТИКА

PROCEEDINGS OF THE ACADEMY OF SCIENCES OF THE ESTONIAN SSR. PHYSICS * MATHEMATICS

$1986,35,4$

удК [535.34+539.291.1] : 547.973.733

Ю. ПАХАПИЛЛЬ

\title{
ФОТОВЫЖИГАНИЕ ПРОВАЛА В СПЕКТРАХ ПОГЛОЩЕНИЯ МОНОМЕРА И ДИМЕРА ЭТИОПОРФИРИНА І В ОРГАНИЧЕСКИХ СТЕКЛАХ
}

(Представил К. К. Ребане)

\section{Введение}

Однородный спектр поглощения и излучения примесных молекул в твердотельных матрицах при гелиевых температурах состоит из узких бесфононных линий (БФЛ) и широких фононных крыльев [ $\left.{ }^{1}\right]$. Ширина чисто электронной БФЛ Г при $T \rightarrow 0$ определяется временем энергетической релаксации $T_{1}$, а при $T>0$ - временем фазовой релаксации $T_{2}$, обусловленным совместным действием энергетической и чисто фазовой релаксаций $T_{2}{ }^{*}: \pi \Gamma=1 / T_{2}=1 / 2 T_{1}+1 / T_{2}{ }^{*}$. Однородная структура спектров примесных молекул обычно скрыта более или менее сильным неоднородным уширением, вызванным статистическим разбросом частот вибронных переходов вследствие не вполне идентичного окружения внедренных в матрицу молекул. Для изучения однородных контуров БФЛ, особенно чисто электронных, а также процессов релаксации широко используется метод фотовыжигания провала в неоднородно уширенных спектрах поглощения, возбуждения и люминесценции $\left[{ }^{2-7}\right]$. Данный метод мы используем для изучения тонкой структуры в спектре поглощения димеров и электрон-фононного взаимодействия в мономерных и димерных примесных молекулах этиопорфирина I (ЭП) в органических стеклах. Механизм фотохимического выжигания провала безметальных порфиринов хорошо известен - в результате поглощения фотонов происходит поворот пары протонов внутри порфиринового кольца $\left[{ }^{8,9}\right]$. В случае ЭП, учитывая его симметрию $D_{2 h}$, фототаутомеризация эквивалентна повороту молекулы на $90^{\circ}$.

Широкополосные спектры поглощения и флуоресценции под обычным (нелазерным) возбуждением ЭП в стеклах при $77 \mathrm{~K}$ исследовались ранее $\left[{ }^{10}\right]$. Было установлено, что в некоторых стеклообразных матрицах (петролейный эфир, метилциклогексан и их смесь с изопентаном) спектры поглощения и флуоресценции могут быть представлены в виде суммы двух спектров - спектра мономера и спектра димера. Применением высоких концентраций ЭП в растворе $\left(c \geqslant 3 \cdot 10^{-4}\right.$ моль/м) при замораживании можно добиться того, чтобы почти вся примесь собралась в димерах.

\section{Методика измерений}

Провал в спектре пропускания (поглощения) выжигали с помощью дефокусированного луча непрерывного лазера на красителе фирмы «Spectra Physics», модель 375 (родамин 6Ж, ширина линии $\delta_{L} \simeq 1 \mathrm{~cm}^{-1}$, 
при измерениях температурной зависимости $\left.\delta_{L} \leqslant 0,2 \mathrm{~cm}^{-1}\right)$, накачиваемого линией $5145 \AA \mathrm{Ar}^{+}$-лазера CR-12 («Coherent Radiation»). Контур провала в спектре пропускания измеряли с помощью монохроматора ДФС-24 с аппаратной функцией $0,4-0,7 \mathrm{~cm}^{-1}$ и лампы накаливания. Гелиевый криостат с объектом помещали между выходной щелью монохроматора и ФЭУ-106, работающим в режиме счета фотонов. Регистрирующая часть измерительной системы состоит из многоканального анализатора NTA-1024, ЭBM EMG-666 и двухкоординатного самописца. Измеряемый спектр пропускания пересчитывали в спектр поглощения на ЭВМ. Растворы ЭП в смеси метилциклогексан-изооктан (МЦГ-ИО) в соотношенин $1: 1$ приготовляли с концентрацией $(0,8-4) \cdot 10^{-4}$ моль/л. Плоскопараллельные кварцевые кюветы (толщина слоя $0,3-1,5$ мм) с растворами погружали в жидкий азот, а после замерзания раствора перемещали в терморегулируемый гелиевый криостат. При температуре $T=4,2$ К объект выдерживали в жидком гелии, а при $T>4,2 \mathrm{~K}$ температуру стабилизировали потоком паров гелия с точностью не хуже $\pm 2 \%$ и измеряли угольным резистором с погрешностью $\pm 3 \%$. Оптическая плотность $A 0-0$-полосы поглощения объектов на частоте выжигания составляла $0,1-1,0$.

\section{Результаты и обсуждение}

Спектры поглощения и флуоресценции при неселективном возбуждении мономеров ЭП в стеклах при $4,2 \mathrm{~K}$ состоят из неоднородно уширенных полос с полушириной $100-150 \mathrm{~cm}^{-1}$. В матрицах Шпольского спектры ЭП более структурные с характерной для эффекта Шпольского мультиплетной структурой $\left[{ }^{11}\right]$. При лазерном возбуждении спектр флуоресценции мономера ЭП в стеклах приобретает линейчатую структуру $\left[{ }^{12}\right]$, т. е. частично удается снять неоднородное уширение. Максимум $0-0$-полосы в спектре поглощения одиночных молекул ЭП в стекле МЦГ-ИО при 4,2 К располагается около $6200 \AA$ (рис. 1). При концентрации ЭП в растворе $\geqslant 10^{-4}$ моль/л в спектре поглощения замороженного объекта появляются новые полосы, самая длинноволновая из которых отстоит от максимума $0-0$-полосы мономера на $200-250 \mathrm{~cm}^{-1}$ в сторону меньших частот (с полушириной $\approx 150 \mathrm{~cm}^{-1}$ в области $6280-6300 \AA ;$ рис. 1 ). По данным $\left[{ }^{10}\right]$, эту полосу мы приписываем димерам ЭП. При селективном лазерном возбуждении $\left(\delta_{L} \simeq 1 \mathrm{~cm}^{-1}\right)$ в области $0-0$-перехода димера в отличие от мономера в спектре флуоресценции димера ЭП при 4,2 К БФЛ нам обнаружить не удалось. Проблема, почему при селективном возбуждении в спектре флуоресценции димера БФЛ не наблюдаются, требует дальнейшего изучения.

Как видно из рис. 2, где приведены участки спектров поглощения мономера $(M)$ и димера $(D)$ ЭП в МЦГ-ИО при 4,2 K до и после облучения объекта лазером в 0 -0-полосе с плотностью мощности $0,5 \mathrm{Mвт} / \mathrm{cm}^{2}$ в течение 10 с $\left(\lambda_{b}=6195 \AA\right.$ для мономера, $\lambda_{b}=6290 \AA$ для диаметра), в результате облучения на частотах лазера в спектрах поглощения мономера и димера ЭП возникают устойчивые провалы с полушириной $\geqslant 1 \mathrm{~cm}^{-1}$. Полуширина провала определяется шириной лазерной линии выжигания. Отметим, что, по данным $\left[{ }^{13}\right]$, однородная ширина БФЛ 0-0-перехода (определяемая по ширине провала в спектре возбуждения) одиночных молекул свободного порфина при 4 K составляет $0,02-0,1 \mathrm{~cm}^{-1}$ и димеров $0,03-0,15 \mathrm{~cm}^{-1}$ в зависимости от выбора стеклообразной матрицы.

При одинаковых дозах облучения при выжигании $(\approx 5$ мДж/см²) глубина ненасыщенного провала в спектре пропускания мономера составляет около $15 \%$, а в спектре димера от 3 до $9 \%$. Более эффективное 


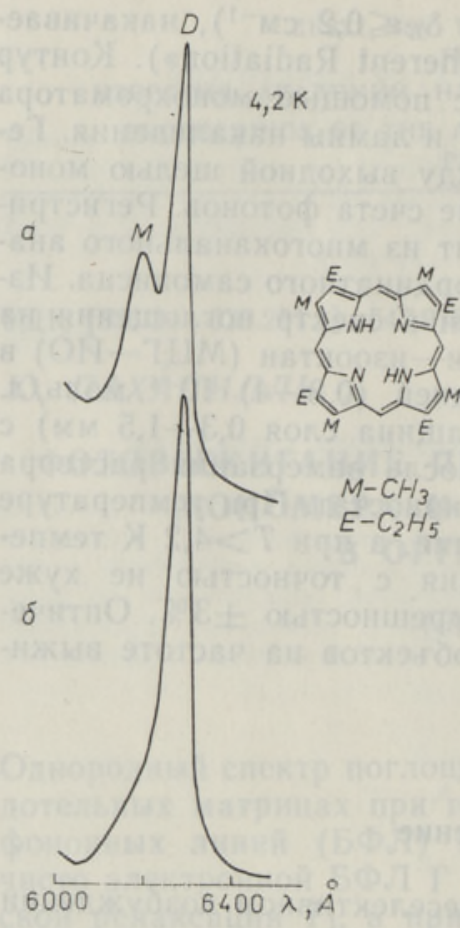

Рис. 1. Спектр поглощения в области 0-0-перехода мономера $(M)$ и димера $(D)$ этиопорфирина I в стекле метилциклогексан-изооктан $(1: 1)$ при 4,2 К. $a-c \simeq 1,8 \cdot 10^{-4}$ моль/л, $б-c \simeq 3 \cdot 10^{-4}$ моль/л.

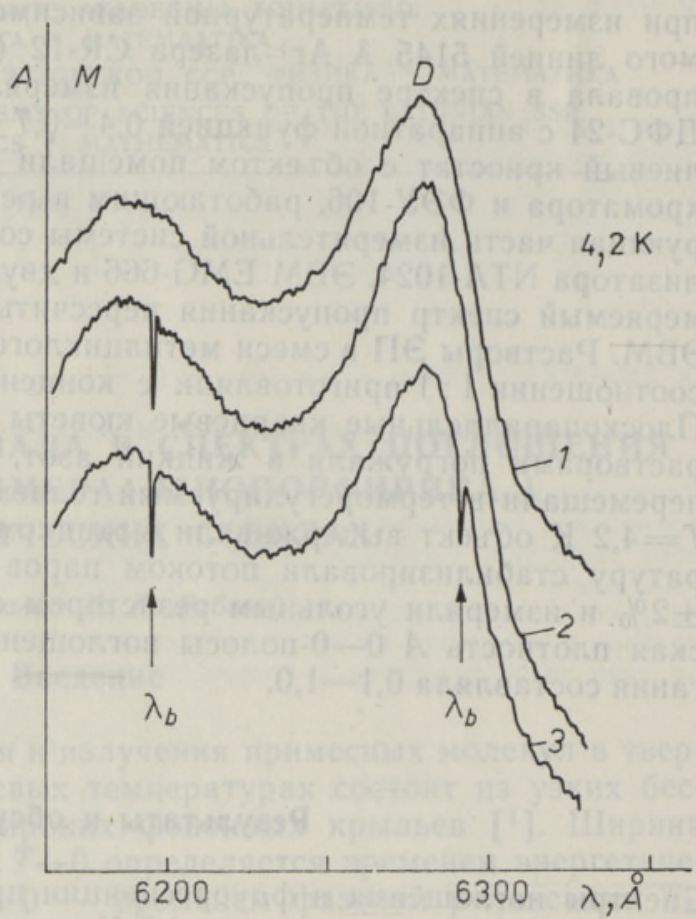

Рис. 2. Спектр поглощения в области 0-0-перехода мономера $(M)$ и димера $(D)$ этиопорфирина I в стекле метилциклогексан-изооктан (1:1) при $4,2 \mathrm{~K}, c \simeq 1,3 \cdot 10^{-4}$ моль/л.

1 - до выжигания провалов; 2 - после выжигания в $0-0$-полосе мономера, $\lambda_{b}=6195 \AA$, доза облучения $\approx 5$ мДж/см²; 3 - после выжигания в 0 -0-полосе димера, $\lambda_{b}=6290 \AA$, доза облу.

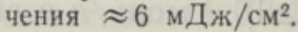

выжигание одиночных молекул объясняется тем, что в случае димера электрон-фононное взаимодействие сильнее и БФЛ слабее, чем в случае мономера. Возникновение узкого провала в спектре поглощения димера ЭП показывает преимущество метода фотовыжигания перед селективным возбуждением флуоресценции. Измерения резонансной флуоресценции молекул в конденсированном веществе затруднены из-за рассеянного света [ $\left.{ }^{14}\right]$.

В результате выжигания мы не обнаружили новых полос в спектрах поглощения мономеров и димеров ЭП в стекле МЦГ-ИО. Это и понятно, поскольку естественно считать, что при фототаутомеризации происходит перераспределение центров в пределах неоднородно уширенной полосы (в матрицах Шпольского наблюдаются сдвиги БФЛ порядка $\leqslant 100$ см $\left.^{-1}\left[{ }^{8,9}\right]\right)$. С целью уточнения перераспределения фотопревращенных молекул мы провели выжигание провалов на нескольких часто-

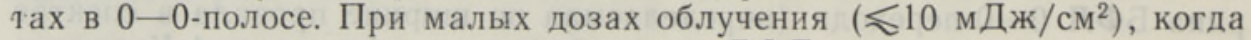
выжигание происходит в основном через БФЛ, можно последовательно выжигать большое количество провалов без значительного заплывания ранее выжженных (рис. 3, $a$, б). При больших дозах облучения

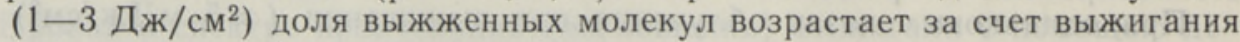
через широкие фононные крылья и в результате перераспределение примесей отчетливо проявляется. Почти полное заплывание заранее выж- 


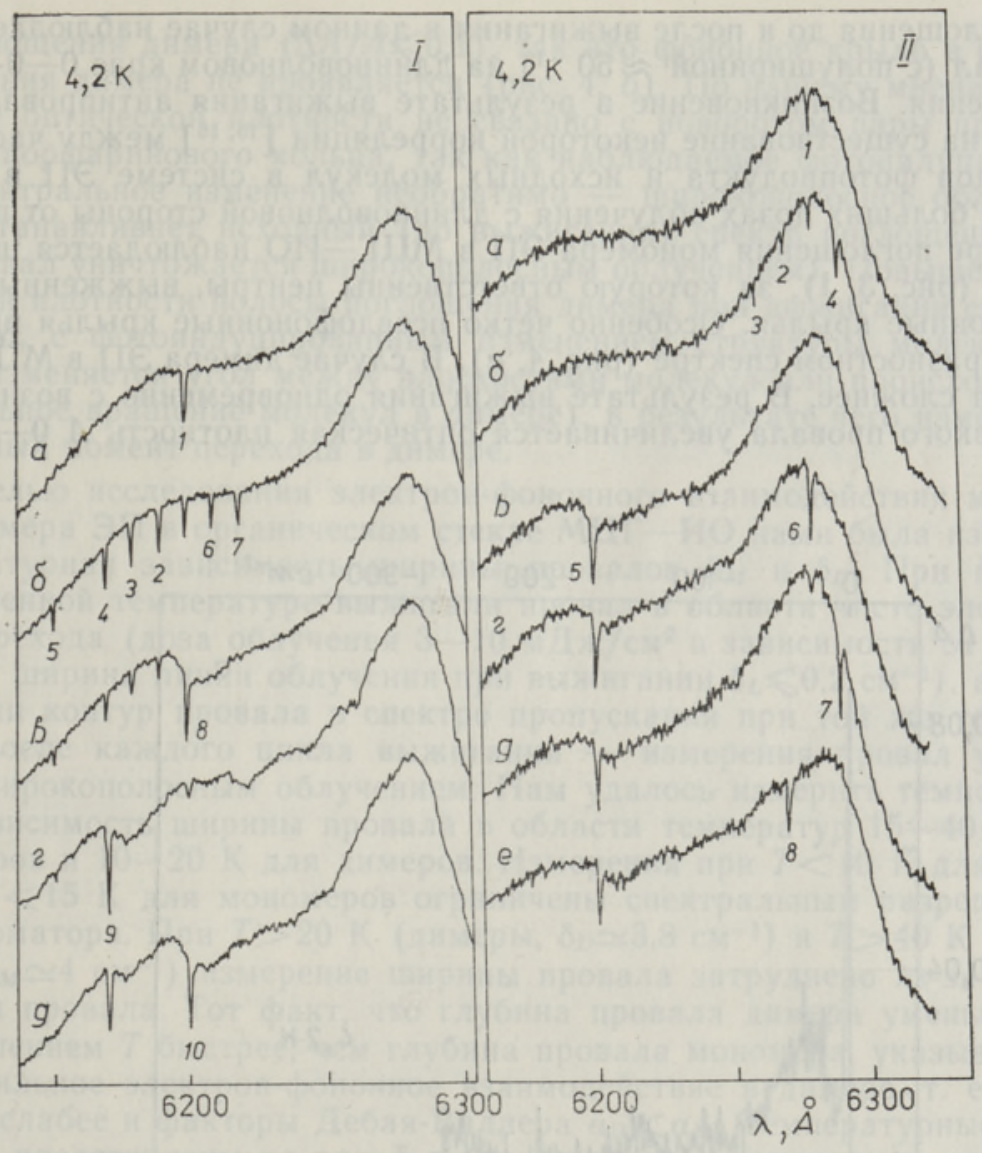

Рис. 3. Спектр поглощения в области 0-0-перехода мономера и димера этиопорфирина I в стекле метилциклогексан-изооктан $(1: 1)$ при $4,2 \mathrm{~K}, c \simeq 1,4 \cdot 10^{-4}$ моль/л. I - выжигание провала в области 0-0-перехода мономера; $a, 6$ - доза облучения

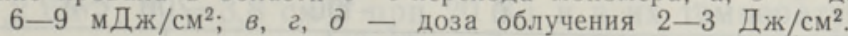

II - выжигание провала в области 0-0-перехода мономера и димера; $a, 6$ - доза

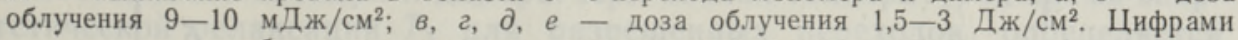
обозначена последовательность выжигания провалов.

женных провалов наблюдается при $\Delta v=v_{i+1}-v_{i}>0$ до $200 \mathrm{~cm}^{-1}$, т. е. происходит обратная фототаутомеризация. В случае $v_{i+1}<v_{i}$ эффективность заплывания значительно меньше и быстро уменьшается при возрастании $\Delta v$. Следовательно, чисто электронные БФЛ поглощения фотопродуктов выжигания располагаются в основном в коротковолновом крае неоднородно уширенной полосы необлученного объекта. Отметим, что фотоиндуцированное заплывание провалов происходит в примеси димера несколько эффективнее, чем в случае мономера (рис. $3, \mathrm{I}, 2, \partial$; II, $\partial, e)$.

Мы исследовали также спектральное перераспределение выжженных молекул ЭП в эфире. При замораживании раствора ЭП в эфире получается стеклообразный объект только с одиночными центрами независимо от концентрации примеси (неоднородная ширина 0 -0-полосы поглощения $\left.\approx 100 \mathrm{~cm}^{-1}\right)$. При выжигании провала в области $0-0$-перехода наряду с равномерным распределением фотопродуктов в разности спект- 
ров поглощения до и после выжигания в данном случае наблюдается антипровал (с полушириной $\approx 50^{-1}$ ) на длинноволновом крае $0-0$-полосы поглощения. Возникновение в результате выжигания антипровала указывает на существование некоторой корреляции $\left[{ }^{15,16}\right]$ между частотами переходов фотопродукта и исходных молекул в системе ЭП в эфире.

При больших дозах облучения с длинноволновой стороны от провала в спектре поглощения мономера ЭП в МЦГ-ИО наблюдается широкая полоса (рис. 3, I), за которую ответственны центры, выжженные через их фононные крылья. Особенно четко псевдофононные крылья проявляются в разностном спектре (рис. $4, a$ ). В случае димера ЭП в МЦГ-ИО картина сложнее. В результате выжигания одновременно с возникновением узкого провала увеличивается оптическая плотность $A$-0-поло-

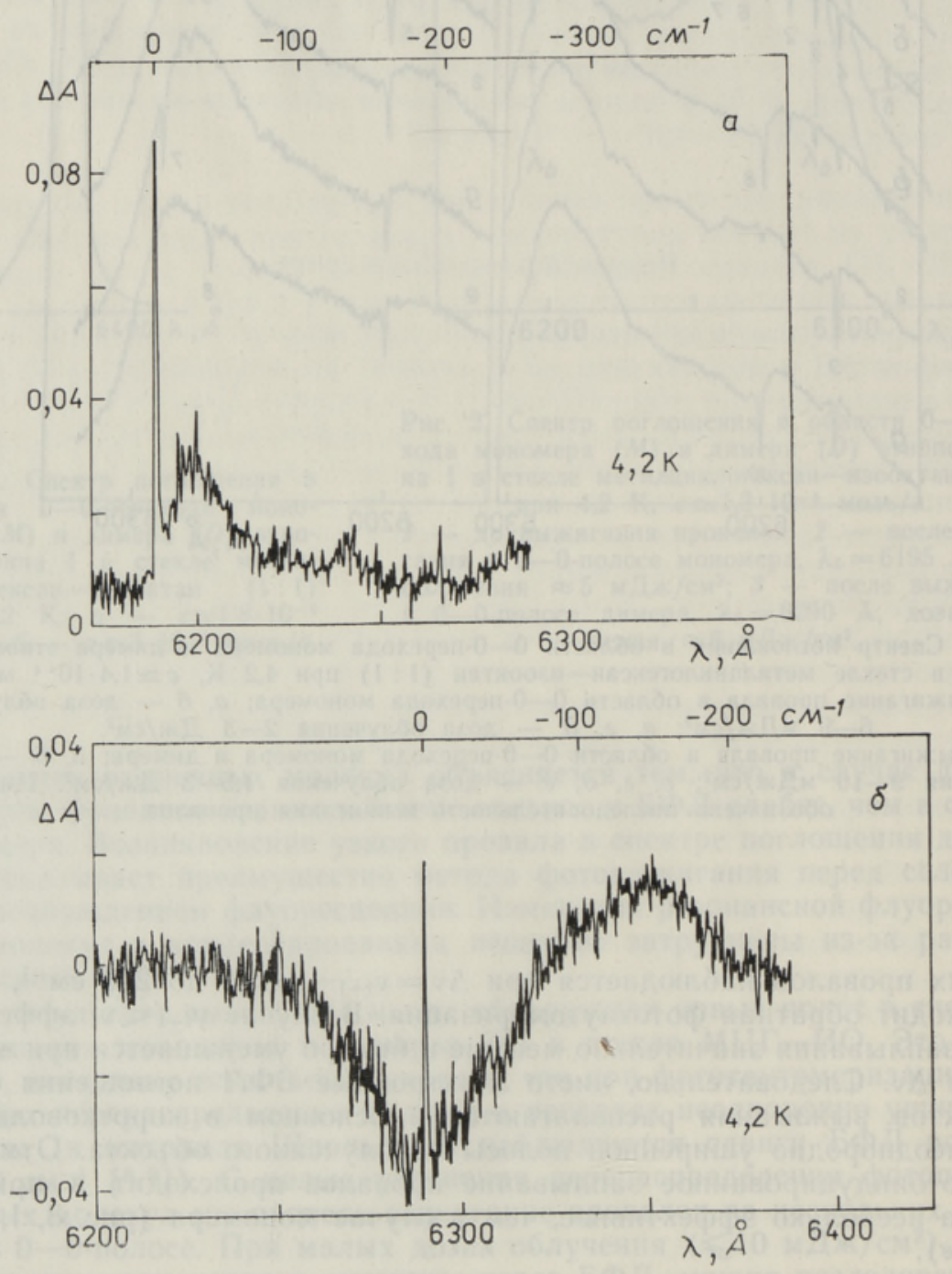

Рис. 4. Спектр выжигания в области $0-0$-перехода мономера $(a), c \simeq 0,9 \cdot 10^{-4}$ моль/л и димера (б), $c \simeq 3 \cdot 10^{-4}$ моль/л этиопорфирина I в стекле метилциклогексан-изооктан (1:1) при 4,2 К. $\Delta A(\lambda)=A_{1}(\lambda)-A_{2}(\lambda)$, где $A_{1}(\lambda)$ - спектр поглощения до выжигания провала, $A_{2}(\lambda)$ - спектр поглощения после выжигания провала, 
сы поглощения димера $(\Delta A / A \leqslant 0,1)$, так что фононное крыло в спектрѐ выжигания димера не проявляется (рис. 4,6$)$. По нашему мнению, увеличение оптической плотности не связано с поворотом пары протонов внутри порфиринового кольца, так как наблюдаемюе фотоиндуцированное спектральное изменение необратимо - широкополосное облучение не восстанавливает исходный (до выжигания) спектр поглощения (узкий провал уничтожается широкополосным облучением). Повышение оптической плотности полосы поглощения димера при выжигании связано, вероятно, с фотоиндуцированным изменением структуры молекул димера (изменяется угол между плоскостями молекул или происходит относительное вращение молекул в димере), в результате чего изменяется дипольный момент перехода в димере.

С целью исследования электрон-фононного взаимодействия мономера и димера ЭП в органическом стекле МЦГ-ИО нами была измерена температурная зависимость ширины провалов $\delta_{M}$ и $\delta_{D}$. При каждой определенной температуре выжигали провал в области чисто электронного перехода (доза облучения $3-10$ мДж/ $\mathrm{cm}^{2}$ в зависимости от температуры, ширина линии облучения при выжигании $\left.\delta_{L} \lesssim 0,2 \mathrm{~cm}^{-1}\right)$, а затем измеряли контур провала в спектре пропускания при той же температуре. После каждого цикла выжигания - измерения провал уничтожали широкополосным облучением. Нам удалось измерить температурную зависимость ширины провала в области температур 15-40 К для мономеров и $10-20 \mathrm{~K}$ для димеров. Измерения при $T<10$ К для димеров и $T<15 \mathrm{~K}$ для мономеров ограничены спектральным разрешением монохроматора. При $T>20 \mathrm{~K}$ (димеры, $\delta_{D} \simeq 3,8 \mathrm{~cm}^{-1}$ ) и $T>40 \mathrm{~K}$ (мономеры, $\delta_{M} \simeq 4 \mathrm{~cm}^{-1}$ ) измерение ширины провала затруднено из-за малой глубины провала. Тот факт, что глубина провала димера уменьшается с повышением $T$ быстрее, чем глубина провала мономера, указывает на более сильное электроп-фононное взаимодействие в димере, т. е. БФЛ димера слабее и факторы Дебая-Валлера $\alpha_{D}<\alpha_{M}$. Температурные зависимости представлены на рис. 5 в $\log -\log$ шкале. Измеряемые значения ширины провалов можно аппроксимировать зависимостью $\delta \sim T^{n}$, где $n=1,66 \pm 0,1$ для мономера и $n=1,8 \pm 0,15$ для димера.

Рассмотрим, с чем может быть связано различие в ширинах провалов $\left(\delta_{M}=1,2 \mathrm{~cm}^{-1}, \delta_{D}=3,8 \mathrm{~cm}^{-1}\right.$ при $\left.20 \mathrm{~K}\right)$ и в их температурных зависимостях для мономера и димера. При низких температурах время энергетической релаксации $T_{1}$ для разрешенных переходов определяется скоростями излучательных и безизлучательных переходов и слабо зависит от температуры [ $\left.{ }^{1}\right]$. Температурная зависимоость однородной ширины чисто электронной линии определяется изменением времени чисто фазовой релаксации $T_{2}{ }^{*}$ возбужденного электронного состояния. Увеличение однородной ширины $0-0$-линии связано с увеличением плотности низкочастотных фононов в стеклообразной матрице при повышении температуры. Соударения этих фононов с возбужденными примесными молекулами приводят к дефазировке (утери «фазовой памяти») возбужденного электронного состояния и уменьшению времени жизни этого состояния $\left[{ }^{13,17-20}\right]$.

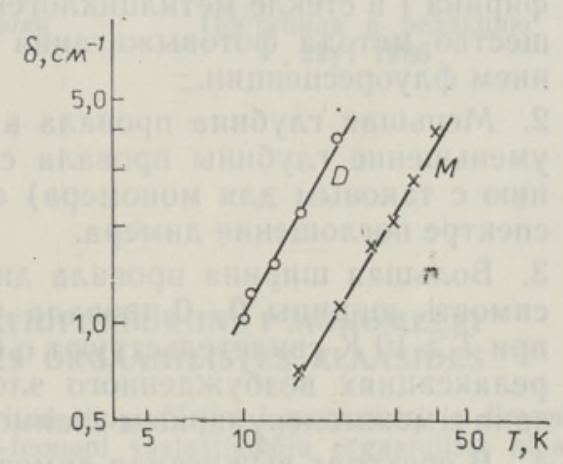

Рис. 5. Температурная зависимость ширины провала $\delta$ мономера $(M)$ и димера $(D)$ этиопорфирина I в стекле метилциклогексан-изооктан $(1: 1)$ в $\log -\log$-шкале. 
Одной из причин, обуславливающей ускорение как фазовой, так и энергетической релаксаций, может быть межмолекулярное взаимодействие в димерах $\left[{ }^{21}\right]$. При образовании димера из одинаковых молекул возбужденные электронные состояния (нас интересует состояние $S_{1}$ ) расщепляются на симметричные $E_{+}$и антисимметричные $E_{-}$состояния. Величина расщепления $\Delta E=E_{+}-E_{-}$определяется силой взаимодействия между молекулами в димере. Учитывая наличие двух электронных состояний $E_{+}$и $E_{-}$, в случае димеров появляется дополнительный канал дефазировки $\left[{ }^{22}\right]$. При температурах $k T \geqslant \Delta E$ фононы матрицы будут индуцировать обмен энергии (рассеяние фононов) между состояними $E_{+}$ и $E_{-}$димера. Этот процесс приведет к сокращению времени фазовой релаксации и к увеличению однородной ширины чисто электронной линии.

Увеличение однородной ширины (ширины провала) димера по сравнению с шириной мономера может быть связано также с энергетической релаксацией. Если величина расщепления $\Delta E$ возбужденного электронного состояния $S_{1}$ димера меньше ширины неоднородного распределения молекул в матрице (по данным $\left[{ }^{10}\right]$, в случае димеров ЭП такая ситуация и имеет место), то в предположении о непараллельности плоскостей молекул в димере, мы возбуждаем димеры как в состояние $E_{+}$, так и в $E_{-.}$Следовательно, определенный вклад в уширение провала могут внести и безызлучательные переходы $E_{+} m \rightarrow E_{-}$, уменьшающие время жизни состояния $E_{+}$. Этот механизм уширения отчасти определяет разницу в ширинах провалов димера и мономера при низких температурах $k T<\Delta E$, когда рассеяние фононов между $E_{+}$и $E_{-}$энергетически маловероятно.

Вышеприведенное обсуждение уширения провала димера и мономера верно в случае, если измеряемая ширина провала определяется только однородной шириной чисто электронного перехода, т. е. на ширину провала не влияет флуктуащионное уширение или спектральная диффузия (зависимость ширины провала от времени цикла выжигания - измерения $\left.\left[{ }^{5,19,23-26}\right]\right)$. При наших измерениях ширины провалов длительность цикла выжигания-измерения составляла $\approx 5$ мин.

\section{Выводы}

1. Хотя БФЛ в спектре флуоресценции димера при селективном возбуждении не проявляются, методом фотовыжигания провала удается исследовать тонкую структуру спектров поглощения димера этиопорфирина I в стекле метилциклогексан-изооктан. Это показывает преимущество метода фотовыжигания провала перед селективным возбуждением флуоресценции.

2. Меньшая глубина провала в спектре поглощения димера и быстрое уменьшение глубины провала с повышением температуры (по сравнению с таковым для мономера) свидетельствуют о более слабых БФЛ в спектре поглощения димера.

3. Большая ширина провала димера и различная температурная зависимость ширины 0 -0-провала у мономера и димера этиопорфирина I при $T>10 \mathrm{~K}$ свидетельствуют о более быстрой фазовой и энергетической релаксациях возбужденного электронного состояния димера, что связано с межмолекулярным взаимодействием в димере.

4. В спектрах выжигания димера этиопорфирина I проявляется индуцированное лазерным облучением изменение структуры димера, выраженное в виде роста коэффициента поглощения.

Автор благодарен К. К. Ребане, Э. Липпмаа, Я. Кикасу и И. Сильдосу за ценные замечания, а также А. М. Шульге за предоставление этиопорфирина I. 


\section{ЛИТЕРА Т У А}

1. Ребане K. К. Элементарная теория колебательной структуры спектров примесных центров кристаллов. М., «Наука», 1968.

2. Гороховский А. А., Каарли Р. К., Ребане Л. А. Письма в ЖЭТФ, 20, вып. 7, 474-479 (1974); Gorokhovskii, A. A., Kaarli, R., Rebane, L. A. Opt. Commun., 16, № 2, 282-284 (1976).

3. Kharlamov, B. M., Personov, R. I., Bykovskayı, L. A. Opt. Commun., 12, № 2, $191-193$ (1974).

4. de Vries, H., Wiersma, D. A. J. Chem. Phys., 72, № 3, 1851-1863 (1980).

5. Rebane, L. A., Gorokhovskii, A. A., Kikas, J. V. Appl. Phys., B29, № 4, 235-250 (1982).

6. Small G. J. In: Modern Problems in Condensed Matter Sciences. Vol. 4. Spectroscopy and Excitation Dynamics of Condensed Molecular Systems (Eds. Agranovich, V. M., Hochstrasser, R. M.). North-Holland, Amsterdam, 1983, 515-554.

7. Friedrich, J., Haarer, D. Angew. Chemie (Int. Ed. in English), 23, № 2, 113-140 (1984).

8. Соловьев К. Н., Залесский Н. Е., Котло В. Н., Шкирман С. Ф. Письма в ЖЭТФ, 17, вып. 9, 463-466 (1973); Котло В. Н., Соловьев К. Н., Шкирман С. Ф., Залесский Н. Е. Изв. АН БССР. Физ. Матем., № 3, 99-107 (1974).

9. Völker, S., vian der Waals, J. H. Mol. Phys., 32, № 6, 1703-1718 (1976).

10. Дворников С. С., Соловьев К. Н., Цвирко М. П. Ж. прикл. спектроскопии, 38, вып. 5, 798-803 (1983).

11. Соловьев К. Н., Шкирман С. Ф., Егорова Г. Д. Вопросы радиофизики и спектроскопии. М., 1970, 49-61; Юдина О. С., Персонов Р. Н. Биофизика, 19, вып. 1, $41-44$ (1974).

12. Романовский Ю. В., Быковская Л. А., Персонов Р. Н. Биофизика, 26, вып. 4, 621-627 (1981).

13. Thijssen, H. P. H., Dicker, A. I. M., Völker, S. Chem. Phys. Lett., 92, № 1, 7-12 (1982); Thijssen, H. P. H., Völker, S., Schmidt, M., Port, H. Chem. Phys. Lett., 44, № 6, $537-539$ (1983).

14. Rebane, K. K., Avarmaa, R. A. Chem. Phys., 68, № 2, 191-200 (1982).

15. Völker, S., Macjarlane, R. M. IBM J. Res. Develop., 23, № 5, 547-555 (1979).

16. Kikas, J., Rätsep, M. Phys. status solidi (b), 112, № 2, 409-415 (1982).

17. Gorokhouskii, A. A., Rebane, L. A. Opt. Commun., 20, № 1, $144-146$ (1977).

18. Rebane, L. A. In: Proc. Int. Symposium «Ultrafast Phenomenon in Spectroscopy». Tallinn, 1979, 89-112.

19. Гороховский А. А., Кикас Я. В., Пальм В. В., Ребане Л. А. Изв. АН СССР. Сер. физ., 46, № 5, 952-956 (1982)

20. Hayes, J. M., Stout, R. P., Small, G. J. J. Chem. Phys., 74, № 8, $4266-4275$ (1981),

21. Fulton, R. L., Gouterman, M. J. Chem. Phys., 35, № 3, 1059-1071 (1961); 41, № 8, $2280-2286(1964)$.

22. Burland, D. M., Zewail, A. H. In: Advances in Chemical Physics. Vol. 40 (Eds. Prigogine, Rice, S. A.). New York, Wiley, 1979, 369-484.

23. Rebane, K. K. J. Luminescence, 31/32, Part II, $744-749$ (1984).

24. Breinl, W., Friedrich, J., Haarer, D. J. Chem. Phys., 81, № 9, 3915-3921 (1984).

25. Molenkamp, L. W., Wiersma, D. A. J. Chem. Phys., 83, № 1, 1-9 (1985).

26. Кривоглаз М. А. Ж. эксперим. и теор. физ., 88, вып. 6, 2178-2184 (1985).

Ннститут химической и биологической физики Академии наук Эстонской ССР
Поступнла в редакцию 22/I 1986

\section{J. PAHAPILL}

\section{SPEKTRAALNE AUGUPOLLETAMINE ETIOPORFORIINI I MONOMEERI JA DIMEERI NEELDUMISSPEKTRITES ORGAANILISTES KLAASIDES}

Spektraalse augupōletamise meetodi abil on uuritud etioporfüriini I monomeeri ja dimeeri neeldumisspektrite peenstruktuuri ja elektroni-foononi vastastikmôju orgaanilises klaasis metüültsükloheksaan-isooktaan $(1: 1)$. Aukude laiuse temperatuuriline sõltuvus näitab, et dimeeri ergastatud elektronolekus toimub faasirelaksatsioon kiiremini kui monomeeri juhul. Selle põhjuseks on dimeeri elektronolekute lōhenemine molekulidevahelise vastastikmõju tōttu. 


\section{J. PAHAPILL}

\section{SPECTRAL HOLE BURNING IN THE ABSORPTION SPECTRA OF ETIOPORPHYRIN I MONOMER AND DIMER IN ORGANIC GLASSES}

Spectral hole burning has been used for the studies of fine structure and electronphonon interaction in the absorption spectra of etioporphyrin I monomer and dimer impurity molecules in the methylcyclohexane-isooctane $(1: 1)$ organic glass. The temperature dependence of $0-0$ hole depth indicates that in the dimer absorption spectrum no-phonon lines are weaker and the Debye-Waller factor is smaller than in the monomer spectrum. We were not able to observe no-phonon lines in the fluorescence spectrum of etioporphyrin I dimers at $4.2 \mathrm{~K}$ under selective $0-0$ excitation $\left(\delta_{L} \simeq\right.$ $\left.\simeq 1 \mathrm{~cm}^{-1}\right)$. The difference in temperature dependence of hole widths $\delta_{M}, \delta_{D}$ at $10-40 \mathrm{~K}$ temperatures, and the larger value of $\delta_{D}$ at a given temperature (e. g., $\delta_{M} \simeq 1.2 \mathrm{~cm}^{-1}$, $\delta_{D} \simeq 3.8 \mathrm{~cm}^{-1}$ at $20 \mathrm{~K}$ ) provides evidence for a more rapid optical dephasing in the excited electronic states of dimers in comparison with the monomer. This is caused by splittings of the excited electronic states as a result of intermolecular interaction in the dimers. We used laser-induced hole filling measurements to investigate the redistribution of photoproducts of monomer and dimer molecules. In the hole burning spectra we observed laser-induced changes of dimer structure, expressed by increased optical density. 